\title{
NATO Information Operations in Theory and in Practice Battling for Hearts and Minds in Afghanistan
}

\author{
róZSA Tibor ${ }^{1}$
}

\begin{abstract}
The value of information has grown dramatically in our societies. We experience the speed of information constantly accelerating and the amount of information generated is also increasing. The use of social media now has a great impact both on our daily life and the Alliance decision making processes. Information Operations concept has evolved significantly in the last, almost, two decades. Lessons learned in the Balkans and in Afghanistan are particularly important for the allied countries. Consequently, member states and NATO must incorporate experience from the battlefield into doctrines.
\end{abstract}

"In all fighting, the direct method may be used for joining battle, but indirect methods will be needed in order to secure victory." The Art of War, by Sun Tzu

\section{Introduction}

The above Sun Tzu quote could be the signature statement concerning the importance of information operations, which are as old as warfare. Winning a battle without a gunshot has always been the ultimate victory over the enemy. The key to fighting in the information domain is about influencing adversary perceptions.

Today's conflict in Afghanistan is also about affecting peoples' hearts and minds. It will be critical for stabilizing the country in the future. NATO's International Security and Assistance Force (ISAF) in cooperation with other international and national actors are doing their best to make Afghanistan a better place to live. ISAF aims to help provide security, and to contribute to a better future for Afghan people. As officially stated:"To carry out its mission, ISAF conducts population-centric counterinsurgency operations in partnership with Afghan National Security Forces."2 The nature of problems military forces face in Afghanistan is complex - asymmetric war, terrorism, illegal arms and drug trade, a multiethnic, underdeveloped nation, corruption - which requires multifaceted solutions. Information Operations (Info Ops) play a major role in ISAF mission as troops on the ground employ a great variety of assets to achieve their objectives including the capacity building of the Afghan state, particularly its security forces. Nevertheless, ISAF efforts are far from enough without making Afghan people believe in common efforts for a better future of Afghanistan and then to commit themselves to it. Afghans have to make up their minds and decide at the end of the day.

Information Operations concept has evolved significantly in the last two decades. Lessons learned in the Balkans and in Afghanistan are particularly important for the allied countries. Consequently, member states and NATO incorporate experiences from the battlefield into doctrines.

1 Officer at the Joint Force Command in the Hungarian Defense Forces, PhD student in Military Science Doctoral School, served as PrT Commander in Afghanistan in 2007-2008. Email: trozsa22@ gmail.com

2 International Security Assistance Force (ISAF): Key Facts and Figures.

http://www.nato.int/isaf/docu/epub/pdf/placemat.pdf (04.01.2013.) 
This article argues that Info Ops play an increasingly important role in Alliance operations and it is reflected both on the battleground and in conceptual papers. It also says that the integrating role of Info Ops has to receive more attention by experts and decision makers. It starts with a short description of national doctrines: the recent evolution of the most influential US doctrine; the UK doctrine which may accumulate century old experiences; and the doctrine of the freshly experienced Hungarian participation. It continues with the presentation of the commonly developed Alliance doctrine, which will be followed by the relevant experiences in Afghanistan based on articles and personal experiences as PrT Commander in Baghlan Province, in the northern region of Afghanistan.

\section{Overview Information Operations'doctrines}

Info Ops have different interpretations among NATO countries as Info Ops doctrine has been evolving for the last decade. It's not surprising that the first Info Ops doctrine was published by the uS Army in 1996, and the latest version has recently been released. As a result of lessons learned from operations over the last decade, major improvements have been made by many countries regarding these doctrines. NATO also published its Allied Joint Doctrine for Information Operations (AJP 3.10) $)^{3}$ on this subject in November 2009. However, different approaches still exist and this topic continues to generate much debate ${ }^{4}$ amongst experts. It is in line with the rapid changes occurring in the information environment in the last couple of years. "The Information Environment comprises the information itself, the individuals, organizations and systems that receive, process and convey the information". We experience that the speed of information constantly accelerates, the amount of information generated is increasing and the use of social media is having a great impact both on our daily life and Alliance decision making processes. The value of information has grown dramatically in our societies. ${ }^{6}$

\section{United States}

The latest uS joint level doctrine, JP 3-13 Information Operations ${ }^{7}$ has been recently published. It is the newest of its kind, and it contains the most recent lessons learned from operations in Iraq and Afghanistan. "Info Ops are characterized as the integrated employment, during, military operations, of information-related capabilities in concert with other lines of operation to influence, disrupt, corrupt, or usurp the decision making of adversaries or potential adversaries while protecting our own." If we compare it with the previous Info Ops doctrine, dated 2006, we can find that almost the same notion is being used in both. The main difference between this one and the doctrine published in 2006 is that it talks about information-related capabilities (IrCs) in general, instead of naming specific capabilities as it did earlier. The new doctrine makes a distinction among these information-related capabilities, however formerly they were categorized as core, supporting and

3 Allied Joint Doctrine for Information Operations AJP-3.10.

http://info.publicintelligence.net/NATO-IO.pdf (04.01.2013.)

4 CHuKA (2009)

5 MC 0422/4 NATO Military Policy on Information Operations p. 2. http://info.publicintelligence.net/NATO-IO-Policy.pdf

6 HAIG (2009) p. 77.

7 JP 3-13 Information Operations, 27 November 2012.

http://www.dtic.mil/doctrine/new_pubs/jp3_13.pdf (13.01.2013.)

8

Ibid. p. I-1. 
related capabilities in previous doctrine. These IrCs are the available tools at the disposal of the commander to affect the cognitive, physical or virtual dimensions of the information environment.

I find it very important that the ultimate goal of Info Ops has slightly changed from achieving information superiority to affect adversary actions in the physical dimension. The previous doctrine, dated 2006 mentioned information superiority more than 20 times while in the new doctrine it is discussed only in relation to information assurance. It was already in the "air", since the uS Army made changes in its FM 3-0 manual $^{9}$ in 2011, where the term information operations was "unburdened" and inform and influence activities were introduced instead of information tasks. Nevertheless the desire to compose the most effective courses of actions to shape the information environment to our favor is still valid.

The new doctrine also puts more emphasis on integrating information-related capabilities throughout the joint operation planning process and stresses the employment of Info Ops in a multinational environment. The doctrine states that the purpose of the integrated use of IrCs is to influence selected audiences. early lessons learned from Iraq and Afghanistan show that integrating Info Ops always lacked clear guidance ${ }^{10}$ which resulted in different implementation. Consequently integrating IrCs is a key question to the whole model and the doctrine gives detailed direction in the context of the influence relational framework. experiences prove that Info Ops is not about possession of capabilities. For that reason the doctrine argues ${ }^{11}$ that it is not the ownership of the capabilities and techniques that is important, but rather their integrated employment in order to achieve desired end state.

Though integrating IrCs is the real challenge for the Info Ops staff at every level, since experiences show that nobody wants to be coordinated because capabilities do not want to "lose their face."

\section{United Kingdom}

The latest joint level Info Ops doctrine ${ }^{12}$ in the uK was published in 2002, which obviously does not reflect any lessons learned from the latest NATO operations. The definition of Info Ops is very similar to the definition in the previous US doctrine. It is defined ${ }^{13}$ as co-ordinated actions to influence an adversary by undermining his will and decision making ability while protecting one's own decision making processes. Influence activities, counter-command activities and information activities are the main aspects of Info Ops. Their focus is on influencing will and affecting those capabilities that directly enable the application of will. In comparison to the current $\mathrm{uS}$ doctrine it is noteworthy to point out that only media operations and CIMIC are mentioned as related activities. It is also important to note that Info Ops activities intend to influence not only adversary and uncommitted groups but allied audiences as well.

After reading the new US doctrine I find JWP 3-80 a bit outdated since it lacks apparent direction on integrating and applying information related capabilities. As it will be discussed later, this doctrine's greatest value is that it served as a solid base for NATO's Info Ops doctrine which was

9 FM 3-0 Operations

http://www.kmimediagroup.com/files/FM3-0.pdf (14.01.2013.)

10 CoxMajor Joseph L. Cox: Information Operations in Operations Enduring Freedom and Iraqi Freedom - What Went Wrong? uS Army School of Advanced Military Studies, Fort Leavenworth, Kansas Ay 05-06

http://www.fas.org/irp/eprint/cox.pdf (13.01.2013.)

11 Ibid. I-5.

12 JWP 3-80 Information Operations

http://ics-www.leeds.ac.uk/papers/pmt/exhibits/2270/jwp3_80.pdf (15.01.2013.)

13 Ibid 2-1. 
published in 2009.It shows how deeply the uK was involved in the creation of AJP 3.10.

No material has been found on the developing uK Info Ops doctrine, but I presume that similarly to the $\mathrm{uS}$ doctrinal changes, the new term will differ from the existing one. According to the latest British Defence Doctrine, ${ }^{14}$ dated November 2011, "Military operations are executed through joint action, a term used to describe the deliberate use and orchestration of military capabilities and activities to realize specific physical and/or psychological effects." ${ }^{15}$ Joint action, as a new term focuses on influencing and effect and is divided into three categories: Fires, Information Activities and Maneuver. This concept officially brings Information Activities up to the level of Fires and Maneuver where originally the only the latter two stayed. According to this new approach Information Activities are used in the place of Info Ops and it is not clear yet what Info Ops will be comprised of.

\section{NATO}

After many years of development NATO's Allied Joint Doctrine for Information Operations was published in November 2009. The common understanding of Info Ops seemed to be crucial for enabling the Alliance to cope with challenges in the information arena. Although finally it was accepted, three member states - uSA, Germany and Italy - had reservations concerning it, which also reflects the different approaches to this issue. The definition of Info Ops is very similar to the $\mathrm{uK}$ one: "Info Ops is a military function to provide advice and coordination of military information activities in order to create desired effects on the will, understanding and capability of adversaries, potential adversaries and other NAC approved parties in support of Alliance mission objectives." ${ }^{16}$ This lengthy description is complemented by another expression of the information activities, which is intended to define influence operations. "Information activities are actions designed to affect information and or information systems. They can be performed by any actor and include protective measures." 17

Not only the term of Info Ops, but the whole Fundamentals of Info Ops are - in section II - closely related to the $\mathrm{uK}$ document. Therefore the focus of Info Ops is the understanding of goals and capabilities of adversaries, potential adversaries or any parties approved by the North Atlantic Council. Although there is no NATO wide accepted term for the effect-based approach to operations it is included in this doctrine. The tools and techniques that produce effects in the battle space are not new, but how to plan and execute operations is the essence of this concept. "It puts a stronger focus on cause and effect versus target-centric attrition."18

Section IV discusses the three inter-related activity areas of information operations. First of all, "activities that focus on influencing perceptions and attitudes of adversaries." Secondly, "information activities that focus on preserving and protecting Alliance freedom of maneuver in the information environment." Finally, "information activities that focus on countering command functions and capabilities, by affecting the data and information that support adversaries and are used in

14 Joint Doctrine Publication 0-01, British Defence Doctrine. https://www.gov.uk/government/uploads/system/uploads/attachment_data/file/33697/20111130jdp001_bdd_ed4.pdf (15.01.2013.)

15 Ibid 5-8.

16 Allied Joint Doctrine for Information Operations I-3. http://info.publicintelligence.net/NATO-IO.pdf (15.01.2013.)

17 Ibid. 1-3.

18 Allied Joint Doctrine for Information Operations 1-5. http://info.publicintelligence.net/NATO-IO.pdf (15.01.2013.) 
command and control, intelligence, surveillance and target acquisition, and weapon systems." 19 Info Ops is not a capability of its own, but it is an integrating function and can employ all necessary capabilities in order to accomplish desired effects. However the doctrine mentions Psychological Operations (PSyOPS), Presence, Posture and Profile (PPP), Operations Security (OPSeC), Information Security (INFOSEC), Deception, Electronic Warfare (EW), Physical Destruction (PD), Key Leader Engagement (KLE), Computer Network Operations (CNO) and Civil-military Cooperation (CIMIC) as the most important capabilities used by Info Ops. Public Affairs (PA) are described as a separate but related function. Beyond coordination of efforts and messages PA has no role in achieving Info Ops objectives.

This doctrine was accepted in November 2009. The new NATO Military Policy on Information Operations has recently been issued establishing a working group in order to incorporate current lessons learned into conceptual papers. I anticipate that theoretical documents will meet practical experiences especially from ISAF mission and nations will have broad-spectrum understanding of planning and executing Info Ops in Alliance missions.

\section{Hungary}

Hungary doesn't have a separate joint level Info Ops doctrine yet, but there is one under development and it is planned to be published in 2014. However NATO AJP 3.10 is fully accepted and used in Alliance operations. Currently both the Joint and the Joint Operations doctrine are under revision in Hungary. There is a section in the currently existing Joint doctrine about Info Ops. It attributes Info Ops as coordinating function to influence adversaries' will and capabilities and protect their own effectiveness and systems. The ultimate goal is information superiority through command and control supremacy. It played an important role in the ISAF mission in Afghanistan, as the complexity of tasks and challenges were previously described.

recent experiences lead to the revision of existing doctrines. As Info Ops is evolving and lessons learned from ongoing operations are utilized in conceptual documents changes are expected in this approach. Info Ops will become an integrating function and its main goal will be influencing adversary actions and behavior.

\section{Information Operations in Afghanistan}

After 11 years of engagement in Afghanistan we still struggle with the "fog of war". Even though we collected plenty of information on culture, religion, ethnic groups and tribes we have little understanding about why people do what they do. We are trained in the code of conduct and are equipped with smart cards telling us the "do's and don'ts" but still face many difficulties in understanding the big picture. We know that this is a different type of warfare and after winning the short war we are still challenged to win the peace. Much of the fight happens in the information battle space from the tactical level up to the strategic stage. All participants want to shape the information environment in their favour, yet every action they may produce intended or unintended effects. In the following part of my study I highlight some of the aspects of information operations' in the ISAF mission in Afghanistan.

19 Ibid. 1-7. 


\section{ISAF}

Info Ops have played an ever increasing role in the ISAF mission since its beginning. Experiences at the beginning show that existing doctrines provided little guidance for planning, integrating and executing Info Ops tasks. As the ISAF mission evolved everybody in the chain of command seemed to realize its importance and besides firepower and maneuver, Info Ops have become the third element of combat power. ${ }^{20}$ It is vital for ISAF to transmit the same message to selected audiences through every channel and at every level. But sending messages is clearly not enough; they should be supported by integrated and cohesive actions at the same time.

To achieve desired effects Info Ops should be applied in a full spectrum of operations instead of limiting it to information superiority. This should begin with a solid conceptual base providing necessary guidance on understanding how Info Ops supports commanders in accomplishing political and military objectives. A clear definition helps realize what Info Ops really is, but we also need obvious understanding on how to integrate and employ related elements. As some doctrines were previously assessed, I think there has been a great development in ISAF mission regarding this issue.

In 2007, when I commanded a PrT in Baghlan Province PSyOPS, CIMIC, KLE, (Key Leader engagement), PPP (Presence, Posture and Profile), INFOSeC and non-kinetic targeting were the main elements of information operations. Non-kinetic targeting was coordinated at the operational level and its main goal was to reach desired effects in the behavior of selected persons. In many cases multiple capabilities were used depending on the specific situation. At that time the operational level (regional Commands) was the lowest where Info Ops posts were authorized in the structure. On the tactical level PrTs mostly had CIMIC, PSyOPS, HuMINT, EW, SIGINT and PA elements at their disposal. According to my experience PrT Commanders soon realized that these capabilities should be employed in synergy to accomplish their mission. In Baghlan Province, we integrated these elements from the start of planning our tasks. The main group whom we wanted to have a positive effect on was the great majority; the "uncommitted" population. It was obvious that in the end they decide whom to support and our goal was to establish an existing communication with them. As part of the target audience analysis process we tried to explore the most efficient channels to reach out to "ordinary" people. One good example was that we particularly supported local TV and radio stations and extensively used them to convey our messages. According to our assessment it proved to be relatively effective, but it is not simple to measure effectiveness in the information domain. The results of surveys and a recorded call-in radio program called "Ask the PrT Commander" showed that at least our messages reached some parts of the population directly. The information campaign we planned and executed was proactive and contained positive communication.

General ISAF narratives on the PrT level were:

- we are here to help and support you

- Afghanistan deserves peace and development

- we will help the Afghan people to find Afghan solutions to their problems

- central and local governments are elected to serve people

- we respect Afghan culture and religion

In addition to these basic messages there were specific campaigns on IeDs, surrendering weap-

20 Commander ISAF Joint Command's Tactical Information Directive, COIN Common Sense. Volume 1. Issue 7. p. 1. http://www.army.mil/article/47177/ 
ons and traffic rules with ISAF convoys. Furthermore PRTs extensively used billboards to advertise any specific projects or programs run by them. Surveys measured the effectiveness of what we did, but we had a very limited indication as to what Afghans really needed in order to find their own solutions to their problems.

There was more reactive communication if something "went wrong" on the strategic or sometimes on the highest political level. even if it turned out later, that the first hand information was not precise, it was hard to succeed in such situations.

Nowadays these narratives are almost the same as it is stated in the tactical directive ${ }^{21}$ issued by the Commander ISAF Joint Command in 2011. Info Ops still puts the population in the center and ISAF facilitates "Afghans communicating with Afghans." At the same time there is more emphasis on informing the public on the Taliban's idea of the future of the country. Afghan people should hear it from their own formal and informal leaders because it is the most convincing way to be informed.

regarding structure, as the information battle evolved, Info Ops posts were introduced not only on the strategic and operational level but on the tactical level as well. until then Info Ops used to be a secondary job for someone from the staff and related capabilities were keen on their separation. These days "at HQ ISAF Info Ops function sits primarily in DCOS Communication's directorate within the Influence and Outreach branch." ${ }^{22}$ This is a relatively small branch headed by a brigadier general. Their mission is to conduct full spectrum information operations in order to influence the behavior of friendly, neutral and enemy groups. To achieve effects close coordination and "horizontally and vertically" integrated efforts are needed. "Horizontal integration is about the link between Say and Do, vertical integration is all about the link between Info Ops staffs at different level." Info Ops working groups make sure at every regional command that their activities are fully synchronized across the country.

Influencing the neutral majority of the civilian population has become the center of gravity of information operations. As the international community begins to withdraw its troops to reinforce our narratives and build up confidence it is even more critical. I am sure that there is enough understanding of the situation in Afghanistan to be able to apply appropriate information activities in this regard. On the other hand to counter effectively Taliban propaganda on longer terms still poses a challenge for ISAF troops on the ground.

\section{Taliban}

The Taliban in Afghanistan have a good reputation of employing their mode of fear propaganda. Even though they do not have a doctrine they make use of information techniques better than expected. "Since their removal from power in late 2001, the initially anti-modern Taliban have increasingly recognized that modern technology and media can (and even must) be utilized in support of their confrontation with the Afghan government and international community." ${ }^{23}$ Taliban quickly adapted to the needs of international media and audiences as well. The videos about $\mathrm{IED}^{24}$ attacks or kidnapped westerners posted on youTube are extensively watched in our societies.

21 Commander ISAF Joint Command's Tactical Information Directive, COIN Common Sense. Volume 1. Issue 7. p. 1. http://www.army.mil/article/47177/

22 Ibid. p.3.

23 FOXLEy, Tim: Countering Taliban Information Operations in Afghanistan http://www.ndu.edu/press/countering-taliban-information-operations.html (16.01.2013.)

24 Improvised Explosive Devices 
Their real aim is not the physical destruction of soldiers or civilians, but they want to generate a non-kinetic effect with a kinetic action. even if the credibility of these videos cannot be verified they reach their aim. In November 2007, BBC broadcasted news that Burkha District in Baghlan Province was recaptured by the Taliban. The next day my team and I had a school opening ceremony in that district and of course the local governor was still in power.

youTube videos would not work in the Afghan villages, because TV sets are only in some Afghan homes, basically in urban areas. However it is remarkable how local commercial media has grown since 2002, this allows people to have alternative sources of information. According to my experience TV is becoming more and more common, but in rural areas radio is still the primary media source.

So called "night letters" are used frequently by Taliban, which are particularly effective in Afghan tribal society. That is why they fear the expansion of radio and TV stations. Taliban are also good at "fear propaganda" when they kidnap or execute someone from the local community because of talking to an ISAF patrol. During my time in Afghanistan I saw interpreters wearing traditional clothes to get to the camp where they changed into jeans. As we come closer to 2014, many of our local civilian employees intend to seek refuge in the countries of ISAF nations. The understanding of local habits and knowing local people is an advantage for face to face communication, which is still a very effective way of transmitting messages in Afghanistan.

Taliban have suffered great losses from airstrikes. Therefore their communication focuses very much on ISAF airstrikes, especially on the deaths of local civilians, the so called "collateral damage." It has a serious effect among civilian and political audiences in the troop-contributing nations. An airstrike in Kunduz, in $2009^{25}$ resulted in 142 deaths including civilians and caused NATO wide humiliation and major political turbulence in Germany. This and other similar incidents lead NATO to reduce its airstrikes in Afghanistan. "Perhaps what the Mujahedeen achieved against Soviet airpower in 1980's with guided missiles, the Taliban are achieving, 20 years later, through the power of guided information." 26

All these examples show how the Taliban manipulate tactical issues in the information environment. But there are many key questions they try to avoid in their communication, such as the Afghan civilian deaths due to IED and suicide attacks, or losses they suffer from well executed ISAF raids. understandably Taliban do not talk about education - especially girls' -healthcare, development, governance, legal issues and public security. As the world opens up to the Afghan people these topics will become the focus of their interest. For example, since 2011, the international community has built a great number of schools, this too is missing from Taliban messages and I know from experience, that girls enjoy going to these schools very much.

\section{Summary}

The new NATO policy on information operations clearly reflects how the Info Ops concept ${ }^{27}$ has developed lately. Info Ops are increasingly important to cope with the demands of recent warfare and integrate those capabilities which enable military forces to influence the battlefield as it was

25 http://www.spiegel.de/international/germany/kunduz-bombing-in-afghanistan-german-defense-ministry-sought-toobscure-the-truth-a-684411.html (16.01.2013.)

26 Tim Foxley: Countering Taliban Information Operations in Afghanistan http://www.ndu.edu/press/countering-taliban-information-operations.html (16.01.2013.)

27 MC 0422/4 NATO Military Policy on Information Operations, http://info.publicintelligence.net/NATO-IO-Policy.pdf (19.01.2013.) 
described.

Although information operations is not a capability of its own it indisputably has become an integrating staff function in order to affect the battle space through information activities. In line with this progress there has been a shift in focus from information superiority to influencing in the physical and cognitive domain. Planning for effects also has become the center in NATO operational planning process. ${ }^{28}$ Much work has to be done in the close future to incorporate the vast experience of ISAF and national experiences in Afghanistan. It could secure more effective and efficient operations in weak or failed states, which seem to be unavoidable in the coming years.

In Hungary as we make efforts not to lose any traditional military capability it is necessary to take into account information related capabilities as well. Capabilities require doctrine, manpower and training. Therefore, the doctrine to be published in 2014 should give a clear guidance why Info Ops is inevitable in modern warfare and should include all information related capabilities such as CIMIC, PSyOPS, HuMINT, EW, SIGINT and PA. Info Ops posts should be established on the operational and strategic level in order to plan the integrated employment of these capabilities. Commanders and staffs are supposed to be trained regularly in Info Ops and planning for information effects should be an essential part of exercises.

\section{References}

Allied Command Operations Comprehensive Operations Planning Directive I-2. http://info.publicintelligence.net/NATO-COPD.pdf (20.01.2013.)

Allied Joint Doctrine for Information Operations AJP-3.10. http://info.publicintelligence.net/NATO-IO.pdf (04.01.2013.)

Allied Joint Doctrine for Information Operations I-3. http://info.publicintelligence.net/NATO-IO.pdf (15.01.2013.)

CHuKA, Neil (2009): Note To File - A Comparison of the Information Operations Doctrine of Canada, the united States, the united Kingdom, and NATO. In: Canadian Army Journal. Vol. 12, No. 2, Summer 2009.

Commander ISAF Joint Command's Tactical Information Directive, COIN Common Sense Volume 1. Issue 7. http://www.army.mil/article/47177/

COX, Joseph L., Major (2006): Information Operations in Operations Enduring Freedom and Iraqi Freedom - What Went Wrong? uS Army School of Advanced Military Studies, Fort Leavenworth, Kansas Ay 05-06. http://www.fas.org/irp/eprint/cox.pdf (13.01.2013.)

FM 3-0 Operations. http://www.kmimediagroup.com/files/FM3-0.pdf (14.01.2013.)

FOXLEy, Tim: Countering Taliban Information Operations in Afghanistan http://www.ndu.edu/press/countering-taliban-information-operations.html (16.01.2013.)

HAIG Zsolt dr. et al. (2009): A kritikus információs infrastruktúrák meghatározásának módszertana. ENO Advisory Kft.

International Security Assistance Force (ISAF): Key Facts and Figures. http://www.nato.int/isaf/docu/epub/pdf/placemat.pdf (04.01.2013.)

Joint Doctrine Publication 0-01, British Defence Doctrine. https://www.gov.uk/government/uploads/system/uploads/attachment_data/file/33697/20111130jdp001_bdd_Ed4.pdf(15.01.2013.)

28 Allied Command OperationsComprehensive OperationsPlanning Directive. p. I-2 http://info.publicintelligence.net/NATO-COPD.pdf (20.01.2013.) 
JP 3-13 Information Operations, 27 November 2012.

http://www.dtic.mil/doctrine/new_pubs/jp3_13.pdf (13.01.2013.)

JWP 3-80 Information Operations.

http://ics-www.leeds.ac.uk/papers/pmt/exhibits/2270/jwp3_80.pdf (15.01.2013.)

MC 0422/4 NATO Military Policy on Information Operations.

http://info.publicintelligence.net/NATO-IO-Policy.pdf (13.01.2013.)

Spiegel Online International: Kunduz Bombing in Afghanistan: German Defense Ministry Sought to Obscure the Truth.

http://www.spiegel.de/international/germany/kunduz-bombing-in-afghanistan-german-defense-ministry-sought-to-obscure-the-truth-a-684411.html (16.01.2013.) 